\title{
Correspondence
}

We welcome letters to the Editor concerning articles which have recently been published. Such letters will be subject to the usual stages of selection and editing; where appropriate the authors of the original article will be offered the opportunity to reply.

Letters should normally be under 300 words in length, double-spaced throughout, signed by all authors and fully referenced. The edited version will be returned for approval before publication.

\section{The effect of the patellar tendon-bearing cast on loading}

Sir,

I read with interest the article in the March 2000 issue by Tanaka et $\mathrm{al}^{1}$ entitled 'The effect of the patellar tendon-bearing cast on loading.'

The investigation seems to miss the point of the function of a patellar-bearing cast. The design, although originally perceived by Sarmiento ${ }^{2}$ as an off-loading device, has in retrospect been seen more as a means of maintaining position and enhancing the support of the soft tissue, thereby improving stiffness around the site of the fracture. There is growing evidence that stiffness is probably the most important factor in inducing stability and healing in fractures and that the overall effect of off-loading is negligible. This was also confirmed by Wardlaw et $\mathrm{al}^{3}$ and Meggitt, Juett and Smith ${ }^{4}$ in the early 1980s. Our own work ${ }^{5}$ confirms their findings that the so-called patellar-bearing boss contributes little to off-loading and has minimal influence on the control of rotation.

The role of a patellar-bearing cast is in the middle period of fracture healing when stiffness of the fracture should be enhanced to encourage the formation of callus. The well-crafted cast which controls rotation and excludes a patellar-bearing boss does exactly that. It seems strange that the off-loading of fractures is thought to be good for them. The work presented by Kenwright and others ${ }^{6}$ made it fairly clear that a little movement at the site of a fracture is good.

DAVID I. ROWLEY, B Med Biol, MD, FRCS

Ninewells Hospital \& Medical School

Dundee, UK.

1. Tanaka H, Nagata K, Goto T, Hoshiko H, Inoue A. The effect of the patellar tendon-bearing cast on loading. J Bone Joint Surg $[\mathrm{Br}]$ 2000;82-B:228-32.

2. Sarmiento A. A functional below-the-knee cast for tibial fractures. $J$ Bone Joint Surg [Am] 1967;49-A:855-75.

3. Wardlow D, McLaughlan J, Pratt DJ, Bowker P. A biomechanical study of cast-brace treatment of femoral shaft fractures. J Bone Joint Surg [Br] 1981;63-B:7-11.

4. Meggitt BF, Juett DA, Smith JD. Cast-bracing for fractures of the femoral shaft: a biomechanical and clinical study. J Bone Joint Surg [Br] 1981;63-B:12-23.

(C)2000 British Editorial Society of Bone and Joint Surgery 0301-620X/00/611439\$2.00

J Bone Joint Surg [Br] 2000;82-B:930-3.
5. Rowley DI, Pratt DJ, Marshall PD, Rees PH. Below knee cast stresses and intra-cast pressures during normal walking. Clin Biomechan 1987;1:177-84.

6. Kenwright J, Richardson JB, Goodship AE, et al. Effect of controlled axial micromovement on healing of tibial fractures. Lancet 1986;2:1185-7.

\section{Author's reply:}

Sir,

We thank Professor Rowley for his comments on our article.

We think that achieving a certain stiffness around the site of the fracture is most important during the treatment of a below-knee fracture, and that proper loading has an important role in accelerating bone union after the middle period of healing. We therefore believe that excessive and/or prolonged unloading is not an appropriate treatment for a below-knee fracture.

We usually use a patellar tendon-bearing cast during the early stage of a below-knee fracture, including fractures around the foot or ankle. Proper unloading is sometimes necessary for children or elderly patients who may have difficulty in walking, depending on the site or the type of fracture.

Our study clarified that the unloading effects of a conventional patellar tendon-bearing cast were approximately $30 \%$. Moreover, we have developed a below-knee walking cast which facilitates rapid improvement and regulation of the effects of unloading.

In 1998, Aita et al $^{1}$ stated that "the indications for the use of patellar bearing casts and braces can be expanded to neuropathic conditions of the foot, osteoarthritis of the ankle and subtalar joints, fracture of the calcaneus, and avascular necrosis of the talus".

Our article does not deny Sarmiento's theory and the clinical usefulness of a conventional patellar tendon-bearing cast. Nevertheless, there is a need for a weight-bearing walking cast which facilitates certain and controllable unloading.

T. GOTO, MD

Kurume University School of Medicine Kurume, Japan.

1. Aita D, Bhave A, Hertzenberg JE, Paley D, Cannada L. The load applied to the foot in a patellar ligament-bearing cast. $J$ Bone Joint Surg [Am] 1998;80-A:1597-602.

\section{Bone mineral density of the radius in patients with Colles' fracture}

Sir,

With reference to the article entitled 'Bone mineral density of the radius in patients with Colles' fracture' in the January 2000 issue, the conclusions of Wigderowitz et al, ${ }^{1}$ that patients with Colles' fracture under 65 years of age require investigation, need elaboration. The measurement of bone mineral density (BMD) in control subjects has shown that the standard deviation of the normal oldage group is so low that many normal subjects over the age of 65 years have a score of T-2.5 at the distal forearm. This does not equate with T-2.5 at the spine or neck of the femur: adjustments have been suggested. ${ }^{2}$ Most of their patients are 'osteopenic' rather than 'osteoporotic'. Fractures of the forearm are a risk factor for future fractures of the hip, but up to age 60 years the lag 
time to hip fracture is about 14 years. ${ }^{3}$ The value of early treatment is uncertain and the use of bisphosphonate is unlikely to be cost-effective, although hormone replacement therapy (HRT) may be considered. In studies of the prevention of hip fractures with alendronate in patients with vertebral fracture, the incidence of hip fracture falls maximally in the first two years: in the third year the rates of incidence in the placebo and treated groups are similar. ${ }^{4}$ Most fractures occur after the age of 65 years. It would be more effective to identify patients who have sustained a Colles' fracture before 65 years and to measure their BMD when they reach their mid-sixties. In patients sustaining a Colles' fracture after 65 years the risk of hip fracture is higher and the lag time to fracture shorter; ${ }^{3}$ it would be reasonable to measure the BMD in these patients. Osteoporosis can be treated with a drug such as a bisphosphonate knowing that a significant reduction in the incidence of fractures occurs during the first year. ${ }^{5}$ Since the risk of further fracture is much higher fewer patients will be treated needlessly and a worthwhile reduction in the incidence of fractures will be achieved.

M. W. J. DAVIE, MD

The Robert Jones and Agnes Hunt Orthopaedic and District Hospital NHS Trust

Oswestry, UK

1. Wigderowitz CA, Rowley DI, Mole PA, et al. Bone mineral density of the radius in patients with Colles' fracture. J Bone Joint Surg [Br] 2000;82-B:87-9.

2. Jones T, Davie MWJ. Bone mineral density at the distal forearm can identify patients with osteoporosis at the spine or femoral neck. $\mathrm{Br} \mathrm{J}$ Rheumatol 1998;37:539-43.

3. Mallmin H, Ljunghall S, Persson I, et al. Fracture of the distal forearm as a forecaster of subsequent hip fracture: a population-based cohort study with 24 years of follow-up. Calcif Tissue Int 1993;52:269-72.

4. Black DM, Cummings SR, Karpf DB, et al. Randomised trial of effect of alendronate on risk of fracture in women with existing vertebral fractures. Lancet 1996;348:1535-41.

5. Pols HAP, Felsenberg D, Hanley DA, et al. Multinational, placebocontrolled, randomised trial of the effects of alendronate on bone density and fracture risk in postmenopausal women with low bone mass: results of the FOSIT study: Foxamax International Trial Study Group. Osteoporosis Int 1999;9:461-8.

\section{Authors' reply:}

\section{Sir,}

We agree that further research is needed in this area and we are already carrying out a much larger study of over 200 patients with Colles' fracture who are being investigated at the time of their attendance at the fracture clinic. Our preliminary results support the conclusions in our paper that many of these patients have a reduced BMD relative to an age-matched control group.

We do not believe that some sites of densitometry are intrinsically better than others, at least for the prediction of the overall risk of future fracture. In a large meta-analysis ${ }^{1}$ it was clear that, at least for the prediction of all future fractures, there was no significant difference between a wide range of densitometric sites. $\mathrm{We},{ }^{2}$ and others, ${ }^{3}$ have drawn attention to the dangers inherent in the inappropriate use of T-scores.

We agree that the frequent use of any bisphosphonate in the patients identified as substantially osteopenic relative to agematched peers is unlikely to be cost-effective. We emphasise in our clinical practice the importance of identifying all the contributory factors for osteopenia including low calcium intake, lack of exercise and smoking before considering the balance of advantage for any drug therapy. We agree that for many patients HRT is a more appropriate regime than the bisphosphonates.

The arguments for and against any form of screening for osteoporosis continue to be unresolved, as is the question of the most appropriate age. In our paper we were anxious to draw attention to the need to regard young patients with Colles' fracture as a special group in whom further evaluation may well be of clinical importance.

C. A. WIGDEROWITZ, MD, PhD

C. R. PATERSON, FRCP

University of Dundee

Dundee, UK.

1. Marshall D, Johnell O, Wedel H. Meta-analysis of how well measures of bone mineral density predict occurrence of osteoporotic fractures. BMJ 1996;312:1254-9.

2. Paterson CR. Osteoporosis and the individual patient. Scot Med J 1998;43:35-6.

3. Wasnich RD. Consensus and the T-score fallacy. Clin Rheumatol 1997;16:337-9.

\section{Displaced supracondylar fractures of the humerus in children}

Sir,

I read with interest the article in the March 2000 issue by O'Hara, Barlow and Clarke ${ }^{1}$ entitled 'Displaced supracondylar fractures of the humerus in children'. They have mentioned that the fractures were classified according to the Wilkins modification of the Gartland system and have gone on to classify the fractures as I, IIA, IIB and III. This is not how Wilkins' modification has been described. $^{2}$ The correct version of the classification is I, II and III with two subgroups in III. A protocol has been suggested for the management of these common, yet difficult fractures based on their version of Wilkins' modification. The classification system appears to have been misquoted in their paper and causes confusion.

\section{S. HARISH, FRCS}

Peterborough Hospitals NHS Trust

Peterborough, UK.

1. O'Hara LJ, Barlow IW, Clarke NMP. Displaced supracondylar fractures of the humerus in children. J Bone Joint Surg $[\mathrm{Br}]$ 2000;82-B:204-10.

2. Wilkins KE. Fractures and dislocations of the elbow region. In: Rockwood CA, Wilkins KE, King RE, eds. Fractures in children. Vol. 3. 4th edition. Philadelphia: Lippincott-Raven Publishers, 1996:680.

\section{Authors' reply:}

Sir,

Wilkins ${ }^{1}$ proposed a modification to the Gartland ${ }^{2}$ system in 1984. He recognised that a displaced supracondylar humeral fracture may be greenstick in nature with an intact posterior cortex. He noted that this greenstick injury may also have a rotary component. A fracture with an intact posterior cortex and angulation only $_{3}$ was termed type IIA and that with a rotary component type IIB. $^{3}$ Gartland made no reference to the greenstick injury in his system, merely classifying it in regard to the severity of displacement: non-displaced, minimal to moderate and severely displaced. In his original article there is a radiograph of a fracture which is completely displaced with no cortical contact and this is classified as moderately displaced.

Wilkins termed the completely displaced supracondylar fracture with no cortical contact as type III. A type-IIIA fracture has 
posteromedial and type IIIB posterolateral displacement. These subtypes determine which neurovascular structures are most likely to be injured and which pin should be placed first. ${ }^{4}$ This subclassification, however, does not affect the ultimate management of these injuries, as both the type-IIIA and the type-IIIB fractures require closed/open reduction and stabilisation with Kirschner (K-) wires. ${ }^{4}$ We believe that it is fundamental in the treatment of these injuries to appreciate the difference between the type-IIA and type-IIB injuries, since this has a direct bearing on their management. Type-IIA injuries rarely require supplementary K-wire stabilisation, whereas we strongly recommend pin fixation of the type-IIB fracture. We did not subclassify the type-III fractures in our series since this would not alter the management.

Mr Harish has commented that the current edition of Fractures in children by Rockwood, Wilkins and King ${ }^{5}$ subclassifies the type-III injury and not the type-II fracture. The possibility of malrotation of the type-II injury is in fact discussed in the text, but it is not represented in the Table on page 680. While this is unfortunate, this text was published before our recommendations for the treatment of the type-IIB injury. We did not cite the current edition in our bibliography and refer Mr Harish to the earlier work of Wilkins ${ }^{3}$ for a more comprehensive discussion of the classification of supracondylar fractures in children. We hope that this has clarified any confusion.

\section{J. O'HARA, FRCS}

I. W. BARLOW, FRCS Orth

N. M. P. CLARKE, ChM, FRCS

Southampton General Hospital, UK.

1. Wilkins KE. Fractures and dislocations of the elbow region. In: Rockwood CA Jr, Wilkins KE, King RE, eds. Fractures in children. Vol. 3. Philadelphia: LB Lippincott, 1984:363-575.

2. Gartland JJ. Management of supracondylar fractures of the humerus in children. Surg Gynecol Obstet 1959;109:145-54.

3. Wilkins KE. Supracondylar fractures of the humerus. In: Operative management of upper extremity fractures in children. AAOS Monograph Series, 1994.

4. Wilkins KE. The operative management of supracondylar fractures. Orthop Clin North Am 1990;21:269-89.

5. Wilkins KE. Fractures and dislocations of the elbow region. In: Rockwood CA Jr, Wilkins KE, King RE, eds. Fractures in children. Vol. 3. Philadelphia: Lippincott-Raven, 1996:680.

\section{Acute compartment syndrome}

Sir,

The article by McQueen et al $^{1}$ in the March 2000 issue entitled 'Acute compartment syndrome: who is at risk?' raises a number of important issues.

Many publications have already defined the high-risk patient. ${ }^{2,3}$ We do not agree that patients suspected of having a compartment syndrome should be monitored, with a fasciotomy if the readings are abnormal. Most surgeons would proceed to fasciotomy if the clinical features dictated, irrespective of pressure recordings.

We also question the authors' figures concerning rates of fasciotomy for their tibial diaphyseal fractures. A flow chart giving information on how the patients presented, the classification of the fracture, the method of treatment and the timing of diagnosis in relation to treatment would have been of greater benefit to the reader. It is also unclear which compartments were involved in each treatment group. This would be of value if contemplating elective fasciotomy.

The rate of fasciotomy is likely to be higher if relying on pressure studies ${ }^{4}$ and we doubt that measurements were recorded in all patients. Diagnosis on the basis of muscle bulging or expression of blood at surgery is likewise of dubious value, as any compartment under pressure would behave in this way. No reference is made to the component of time. ${ }^{5}$

Our own experience is that pressure monitoring is rarely performed outside dedicated units, and departments with a device seldom use it to its full potential. Perhaps surgeons are happy with their clinical skills for what is, in reality, a rare condition. Other reasons for not monitoring pressure include lack of experience in positioning sensors, lack of knowledge of whether pressures need to be measured at different sites within each fascial space, and the unknown accuracy of the monitors available.

In the light of increasing litigation, are we now negligent if we do not follow the recommendations from a leading unit? The Journal of Bone and Joint Surgery has previously published work from this centre and must be careful to balance authors' recommendations with reality, especially if the conclusions do not quite fit the data.

\section{R. ROACH, FRCS Ed}

R. PERKINS, FRCS

Princess Royal Hospital

Telford, UK.

1. McQueen MM, Garston P, Court-Brown CM. Acute compartment syndrome: who is at risk? J Bone Joint Surg [Br] 2000;82-B:200-3.

2. McQueen MM. Compartment syndromes. Management of Open Fractures. Chapter 20, 1996:263-80.

3. Mubarak SJ. A practical approach to compartment syndrome, Part 2. AAOS Instructional Course Lecture 32.

4. Ovre S, Hvaal K, Holm I, et al. Compartment pressure in nailed tibial fractures: a threshold of $30 \mathrm{mmHg}$ for decompression gives $29 \%$ fasciotomies. Arch Orthop Trauma Surg 1998;118:29-31.

5. Hargens AR, Mubarak SJ. Current concepts in the pathophysiology, evaluation and diagnosis of compartment syndrome. Hand Clin 1998;14:371-83.

\section{Author's reply:}

\section{Sir,}

We note with interest your correspondents' comments. There have been no previous studies of acute compartment syndrome in a defined population to identify the groups of patients who are at most risk of developing the condition.

The recommendation that patients at risk of acute compartment syndrome should undergo tissue pressure monitoring is based on work published four years ago from this unit. At that time we established that the safest threshold for fasciotomy is a differential pressure of $30 \mathrm{mmHg}$ between the diastolic pressure and the tissue pressure. ${ }^{1}$ In that paper we stated that use of the tissue pressure without reference to the diastolic pressure results in unnecessary fasciotomy. This was confirmed by Ovre et al. ${ }^{2}$ The rate of fasciotomy in this unit has remained the same despite the introduction of continuous monitoring over 15 years ago.

The advantage of continuous pressure monitoring is that the diagnosis of acute compartment syndrome is made at a mean of 16 hours earlier than occurs when the surgeon relies on clinical findings. ${ }^{3}$ This results in a significant reduction in the disabling complications of the neglected acute compartment syndrome. Perhaps surgeons should not be happy with their clinical skills for diagnosing a condition which, with an incidence of around $4 \%$, cannot be considered rare. Lack of experience should not be cited as a reason for not using a technique with proven benefits.

The comments about litigation are timely. One of the commonest causes of claims of negligence against orthopaedic surgeons is neglect of an acute compartment syndrome. We recommend continuous monitoring because we feel that the medi- 
cal rather than the legal profession should be driving advances in the management of patients.

M. M. MCQUEEN, MD, FRCS Ed (Orth)

The Lothian University Hospitals NHS Trust

Edinburgh, UK.

1. McQueen MM, Court-Brown CM. Compartment monitoring in tibial fractures: the pressure threshold for decompression. J Bone Joint Surg [Br] 1996;78-B:99-104.

2. Ovre S, Hvaal K, Holm I, et al. Compartment pressure in nailed tibial fractures: a threshold of $30 \mathrm{mmHg}$ for decompression gives $29 \%$ fasciotomies. Arch Orthop Trauma Surg 1998;118:29-31.

3. McQueen MM, Christie J, Court-Brown CM. Acute compartment syndrome in tibial diaphyseal fractures. J Bone Joint Surg $[\mathrm{Br}]$ 1996;78-B:95-8.

\section{Test of stability as an aid to decide the need for osteotomy in association with open reduction in developmental dysplasia of the hip}

Sir,

I would like to comment on the article in the January 2000 issue by Zadeh et al ${ }^{1}$ entitled 'Test of stability as an aid to decide the need for osteotomy in association with open reduction in developmental dysplasia of the hip'. In the main I agree with the authors' suggestion of the use of an intraoperative test of stability after open reduction. I would like to comment, however, on some points of their operative technique.

I disagree with regard to the delay of surgery until about 11 to 12 months after failed conservative treatment. In my experience of children treated surgically under 18 months, those between seven and 12 months seem to have the best results. Walking may have adverse effects and the presence or absence of radiological evidence of the femoral capital epiphysis seems to have no effect on the results. ${ }^{2,3}$ Of the authors' 95 hips, 51 are in patients younger than two years at the time of surgery. Did the authors perform bony procedures besides open reduction in children under 18 months? In my opinion, soft-tissue procedures alone are most effective under 18 months.

I believe that over two years all grade-IV and some grade-III dislocated hips ${ }^{4}$ need femoral shortening osteotomy and femoral varus and derotation osteotomies to avoid 'tight reduction' if preoperative traction has not been used. This need is more obvious in the presence of an acetabuloplasty. The authors' series of patients has 28 grade-IV hips and only five have needed femoral shortening osteotomy. How many of the remaining 23 hips have been operated on in children over two years of age and in how many has an innominate or a Pemberton osteotomy been performed? These ratios may help to explain the significantly higher rate of avascular necrosis and premature physeal arrest in gradeIII and grade-IV hips in the authors' series.

H. ÖMEROĞLU, MD

Osmangazi University Hospital Turkey.
1. Zadeh HG, Catterall A, Hashemi-Nejad, Perry RE. Test of stability as an aid to decide the need for osteotomy in association with open reduction in developmental dysplasia of the hip: a long-term review. $J$ Bone Joint Surg [Br] 2000;82-B:17-27.

2. Ağuçs H, Uçcar H, Ömeroğlu H, Biçcimoğlu A, Tümer Y. Evaluation of the risk factors of avascular necrosis of the femoral head in developmental hip dysplasia under 18 months of age. Procs 19th Meeting European Pediatric Orthopaedic Society 2000, Milan, Italy.

3. Mergen E, Adyaman S, Ömeroğlu H, Erdemli B, Isiklar U. Medical approach to open reduction for congenital dislocation of the hip using the Ferguson procedure: a review of 31 hips. Arch Orthop Trauma Surg 1991;110:169-72.

4. Tönnis D. Congenital dysplasia and dislocation of the hip. Berlin, etc: Springer-Verlag, 1987:80-3.

\section{Authors' reply:}

Sir,

We thank Dr Ömeroğlu for his interesting comments. The issue of timing of open reduction for developmental dysplasia of the hip is highly controversial and will not be fully resolved until it is subjected to a long-term prospective, randomised trial. We are not aware of such a project. Our study shows that open reduction with concomitant osteotomy in the age group of one to two years is associated with good or excellent results in $94 \%$ at skeletal maturity (Severin groups I and II). It is therefore for others to show that earlier surgery carries a better prognosis. Furthermore, our results apply to open reduction through a Smith-Petersen approach and could not directly be compared with other methods such as a medial approach with shorter follow-up. ${ }^{1}$

Of the 51 hips in the age group of one to two years, only two children had no concomitant osteotomy. Most (47) had an upper femoral varus and derotation osteotomy and two an innominate procedure.

In this series all children had preoperative traction for one to two weeks and most hips were therefore easily reduced without tension when the soft-tissue contractures/blocks were overcome during the open reduction. We would agree that femoral shortening is an appropriate procedure in certain cases. The senior author (AC) considers using femoral shortening when the femoral head will not easily reduce with the hip in neutral position and the knee in extension. In this series five hips were judged to require shortening, but this did not guarantee complete protection against avascular changes. In two hips (40\%) premature physeal arrest was noted during the adolescent growth spurt. The serial radiographs of one of these cases appear in the original paper (Fig. 3).

H. G. ZADEH, FRCS Orth

A. CATTERALL, MCh, FRCS

The Royal National Orthopaedic Hospital Trust

Middlesex, UK.

1. Mergen E, Adyaman S, Ömeroğlu H, Erdemli B, Isiklar U. Medical approach to open reduction for congenital dislocation of the hip using the Ferguson procedure: a review of 31 hips. Arch Orthop Trauma Surg 1991;110:169-72. 